\title{
Effect of coronary care on myocardial infarct mortality
}

\author{
B. L. CHAPMAN \\ From the Department of Medicine, The Royal Newcastle Hospital, Newcastle, NSW 2300, Australia
}

SUMMARY To study the effect of coronary care on the hospital mortality rate of acute myocardial infarction, patients treated in a coronary care unit (CCU) were compared with patients treated in general wards. To assess the comparability of cases, the coronary prognostic index of Chapman and Gray (1973) was modified. The modified index was based on serum aspartic aminotransferase (AST) level and cardiogenic shock. Modification was necessary because oliguria, the third variable on which the original index was based, could not always be determined for general ward cases. This modified index assessed very accurately the prognosis of myocardial infarct patients treated in hospital. Patients treated in the coronary care unit had a significantly higher mean modified prognostic index than control patients treated in the general wards, either before or after the introduction of coronary care. They also had a significantly shorter mean delay in admission than either group of general ward cases. These differences would be expected to worsen, not improve, the results of coronary care. By contrast, the two groups of general ward patients were very similar, as shown by mean modified prognostic index, mean admission delay, and results of correlation and regression analysis. In spite of their higher mean modified prognostic index and shorter mean admission delay, the coronary care unit patients had a significant reduction in their mortality rate, which dated from the opening of the unit, to little more than half that for the general ward patients. For general ward patients treated after the introduction of coronary care, on the other hand, the mortality rate was not significantly different from that for ones treated before. Furthermore, the reduction in mortality for coronary care unit cases was approximately the same over the whole range of infarct severity, and did not vary significantly from 15 per cent as the modified index rose from minimum to maximum values. It is suggested that severity of infarction should no longer be a reason for excluding any patients from coronary care.

Controversy continues about the effectiveness of coronary care (Donaldson, 1978; Hill et al., 1978). There is little published evidence that the mortality rate of acute myocardial infarction is lower for patients treated in a coronary care unit than for those treated elsewhere, in groups of patients shown otherwise to have a similar probability of dying (Lindholm et al., 1976; Peterson, 1978). This is in spite of the fact that the earliest coronary care units were established over a decade and a half ago (Brown et al., 1963; Day, 1963; Wilburne and Fields, 1963), and notwithstanding numerous reports on the subject. Furthermore, while it seems that most cardiologists believe that coronary care units do improve the overall prognosis of acute myocardial infarction, it is also commonly believed that any reduction in mortality is greatest in patients with mild or only moderately severe

Received for publication 20 December 1978 infarcts, but small or non-existent in those with very severe infarcts (Chapman, 1970). For this reason, and because of the scarcity of facilities and staff, it has even been suggested that intensive coronary care be reserved either chiefly (Sloman and Brown, 1970) or exclusively (Robinson, 1965; Wyman and Hammersmith, 1968) for patients with less severe infarcts, or that these be treated in separate units from severe cases (Flynn and Fox, 1967).

It will now be shown that, for groups of patients with myocardial infarcts of similar severity as determined by a modified version of the coronary prognostic index of Chapman and Gray (1973), the hospital mortality was significantly less in patients treated initially in a coronary care unit than for those treated throughout in general wards, either before or after the introduction of coronary care. It will also be shown that the magnitude of this mortality reduction was approximately the same 
for infarcts of all degrees of severity, and did not vary significantly from 15 per cent over the whole range of the prognostic indices.

\section{Patients and methods}

Patients studied and methods used have already been described in detail (Chapman, 1970, 1971a, b; Chapman and Gray, 1973). Criteria for diagnosing acute myocardial infarction included a consistent clinical setting with at least one of the following: pathological $Q$ waves or loss of $R$ wave progression in the $\mathrm{V}$ leads, with serial ST segment and $\mathrm{T}$ wave changes; a serum AST level above 40 SigmaFrankel units $/ \mathrm{ml} ;^{\star}$ a serum $\mathrm{LDH}$ level above 550 Berger-Broida units $/ \mathrm{ml}$; positive necropsy findings. Cardiogenic shock was diagnosed if hypotension (BP $\leq 80 \mathrm{mmHg}$ ) and cyanosis and coldness of the extremities persisted for more than half an hour after pain relief and oxygen administration. (Because on multiple regression analysis it was found to make a statistically significant independent contribution to mortality, oliguria was analysed separately from the syndrome so defined.) For the AST estimations, blood was taken at 24 hours from the time of onset of the symptoms of the episode responsible for admission. The admission delay was the time elapsing between the onset of symptoms and arrival at the place of initial coronary care, whether general ward or coronary care unit.

\section{MODIFIED CORONARY PROGNOSTIC INDEX}

Severity of infarction was assessed using a modified version of the coronary prognostic index previously described by Chapman and Gray (1973). To arrive at this original index, more than 150 factors had been examined, and those found to be associated with a statistically significant change in the mortality rate according to $x^{2}$ tests were subjected to multiple regression analysis. These factors included personal characteristics and habits, past history, coexistent disease, details of the admission episode, cardiac and extracardiac complications, arrhythmias, conduction defects, clinical observations, electrocardiogram, chest $x$-ray, and biochemical and haematological investigations. Multiple regression analysis was used to quantify the contribution of each factor to the outcome. Weighted scores were derived from the regression coefficients of a final multiple regression equation containing the only three variables found to have a significant inde-

^The AST levels were measured in Sigma-Frankel units $/ \mathrm{ml}$. These units, rather than the now standard international units $/$, are still given because there is no direct or constant conversion factor between the two measurements (J. E. Dickeson, 1975, personal communication). pendent influence on mortality, and the coronary prognostic index was based on these. Computers were used for all these statistical procedures (Chapman and Gray, 1973). Modification of this index was necessary to allow the inclusion in the present study of an adequate sample of general ward cases, because urine volume was not recorded routinely in the general wards; oliguria was one of the prognostic factors included in the original form of the index.

The modified prognostic index was based on the remaining two of the three variables used in the original index, namely AST level and cardiogenic shock. For its construction, multiple regression analysis was carried out once more on the data for the 357 cases on which the original index was based, but now correlating the outcome with only these two variables. The multiple correlation coefficient was highly significant $(R=0.504, P \ll 0.01)$, as was the partial correlation coefficient for each of the variables (AST, $r=0.271$; shock, $r=0.395$; for each, $P<0.0002)$.

The new prognostic scores were calculated from these partial correlation coefficients, as previously described (Chapman and Gray, 1973). They are shown in Table 1. After these scores were applied to the same 357 cases, there was found to be a highly significant linear correlation between mortality rate and modified prognostic index (Fig. 1) $(r=0.913, P<0.0002)$. According to the coefficient of determination $\left(r^{2}\right), 83.4$ per cent of the variation in mortality rate was explained by variation in the modified prognostic index. The standard error of estimate was $8 \cdot 1$ per cent.

\section{PATIENTS}

To determine the effect of treatment in the coronary care unit on mortality rate, three groups of patients were studied and the modified prognostic index was used to assess their comparability according to severity of infarction, and hence probability of dying. Of these three groups, one was treated in the general wards before the introduction of coronary care and the remaining two groups after this, one initially in the coronary care unit and the other concurrently in the general wards. The patients treated before the introduction of intensive coronary care were discharged from hospital or died there in the two-year period between 1 July 1966 and 30 June 1968, while those treated subsequently were admitted during the 18-month period between the opening of the unit on 20 August 1968, and 19 February 1970. Patients discharged from or dying in the general wards during the seven-week interval between these two periods had a mortality rate of 33 per cent, virtually identical with the 32 per cent 
Table 1 Scores for modified coronary prognostic index

\begin{tabular}{lrc}
\hline Factor & & Score \\
\hline AST level* & $\leqslant 40$ & 0 \\
& $41-80$ & 5 \\
& $81-120$ & 11 \\
$121-160$ & 16 \\
$161-200$ & 22 \\
Cardiogenic shock & $\geqslant 201$ & 27 \\
& Absent & 0 \\
& Present & 40 \\
\hline
\end{tabular}

$\star$ In Sigma-Frankel units/ml.

prevailing in the preceding 12 months (Chapman, 1970), and will not be considered further here. The coronary care unit cases analysed in order to construct the modified prognestic index were admitted during the first 21 months of the operation of the unit, whereas this study was concerned only with admissions during the first 18 months

Every patient admitted to the coronary care unit was recorded in a register, and studied prospectively (Chapman, 1970). Sixty-four per cent of these admissions proved to have acute myocardial infarction; the remainder are not considered further. Another register was kept of infarct patients treated in the general wards during the same period. Most of these were also studied prospectively,

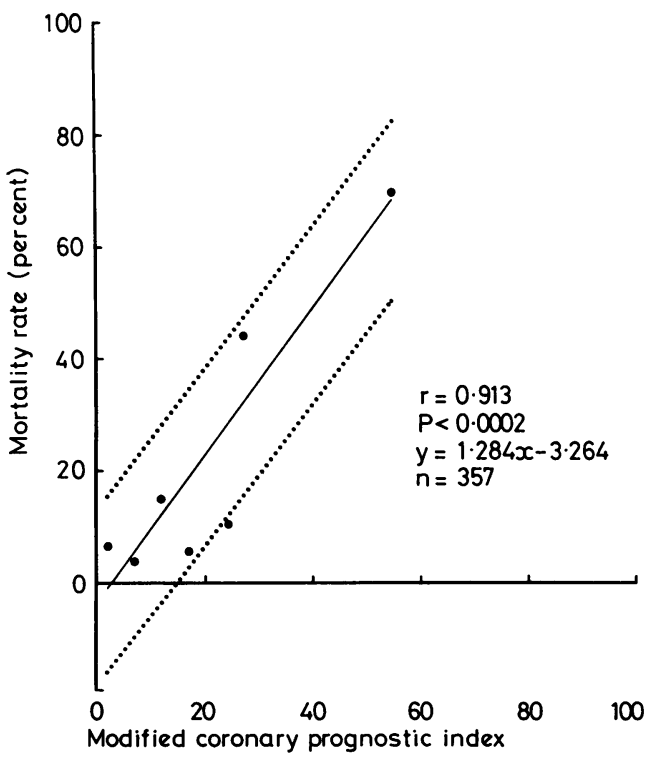

Fig. 1 Coronary care unit cases, 20 August 1968 to 19 May 1970. In this Figure and subsequent Figures the dotted lines are drawn at twice the standard error of estimate from the calculated regression lines. though some not notified at the time were subsequently obtained from the medical records, which were searched systematically. General ward patients treated before the introduction of coronary care were studied retrospectively from the medical records.

\section{ADMISSION POLICY}

Although the original intention was to treat all cases of known or suspected acute myocardial infarction in the coronary care unit once this was operating, whether a patient was in fact admitted there or to a general ward depended principally on the availability of an empty bed in the unit at the time of admission. Patients with infarcts of any severity were accepted, and there was no age limit. However, it was realised that in some cases intensive coronary care would be inappropriate because of dementia, severe incurable coexistent disease, or old age associated with generally failing health. Nevertheless, some patients in these categories were admitted to the unit, and are included in its results. When there were more patients requiring admission than available beds in the unit, preference was given to those who were younger or otherwise healthier. If the episode of infarction was believed to have occurred more than 48 hours before presentation, a patient was usually not accepted for the coronary care unit unless there was a persistent conduction defect or other arrhythmia, but he might still be admitted to a general ward. Of the infarct patients who were already in the general wards, either because the diagnosis was not suspected on admission or because infarction occurred there (or in an operating theatre) during treatment of another complaint, some were treated in the wards, while others were transferred to the coronary care unit. The admission delay for the latter was still calculated from the time of arrival in the unit. Some patients with very severe infarcts whose treatment would have disturbed the calm of the coronary care unit were managed in a nearby intensive care unit, but still entirely by coronary care unit staff, both medical and nursing, according to the same principles of treatment. They, too, are included in the coronary care unit results.

For coronary care unit patients, admission as soon as possible after the onset of infarction was urged. Those referred from outside the hospital were admitted directly into the unit, not being reviewed in the casualty department unless priorities had to be established, while referrals from casualty itself or medical out-patients were also moved to the unit as soon as possible. Losing time to confirm the diagnosis of infarction, even by taking an electrocardiogram, was discouraged. 


\section{TREATMEN T}

Treatment was not uniform for patients in the general wards, either before or after the introduction of coronary care, and seldom included the use of antiarrhythmic agents or modern resuscitation, and never cardioversion or pacing. In the coronary care unit, by contrast, patients were managed strictly according to a procedure based on contemporary practice, with a specially trained team of doctors and nurses providing continuous cardiac monitoring and prompt treatment of conduction defects and other arrhythmias, myocardial failure, and cardiac arrest (Chapman, 1970, 1971a). There was an increasing tendency after the establishment of the coronary care unit for treatment in the general wards to resemble that given in the unit, and also for unit staff to be called for resuscitations, but with neither monitoring nor continuous observation little effective treatment of arrhythmias was possible.

\section{ADDITIONAL NOTES ON STATISTICS}

Some of the subgroups into which patients were divided according to their modified coronary prognostic index scores contained too few cases ( 15 or fewer) for percentage mortality rates to be calculated. As before (Chapman and Gray, 1973), these were combined into larger subgroups, but this did not significantly affect the mortality trends or results of regression analysis. Varying numbers in the subgroups meant that the subgroup intervals selected did not always correspond in the three groups of patients studied (from general wards before and after coronary care, and coronary care unit).

The significance of the correlation coefficients, and of the differences between means, independent constants, and regression coefficients was calculated using standard statistical tests, as described by Yeomans (1968).

The lower proportion of coronary care unit cases whose modified coronary prognostic index could be calculated, compared with general ward cases (307/432 vs. $414 / 476$ and $157 / 193)$, had several possible explanations. Coronary care unit patients had an electrocardiogram taken more promptly after admission and of those who died more came to necropsy, so that relatively more of those dying less than 24 hours after the onset (at which peak AST level was estimated) may have had the diagnosis of infarction established by these other methods. Thus the proportion of infarcts in whom the diagnosis was proven may have been higher in the coronary care unit than in the general wards, without any corresponding increase in the number of cases whose modified prognostic index, needing an estimation of AST level, could be calculated. In the coronary care unit, also, the time at which blood was taken for the AST estimations was more accurately recorded, so that relatively more cases may have been rejected because of documented departures from the required 24-hour postinfarction timing of these (Chapman, 1971b; Chapman and Gray, 1973), which were not infrequent.

Nevertheless, the cases whose modified prognostic index could be calculated still constituted a representative sample of the whole group treated in the coronary care unit, as judged by the incidence of all other factors associated with a statistically significant change in mortality rate (B. L. Chapman, unpublished observations). Furthermore, their mortality rate of 16.3 per cent was not significantly different from the $19 \cdot 2$ per cent for the 125 patients whose modified prognostic index could not be calculated $(P>0.50)$. The slightly lower mortality rate for those whose modified prognostic index could be calculated is explained by the fact that AST level does not reach its maximum until 24 hours after infarction, while the highest mortality rate occurs within that time (Chapman, 1970, 1971a, b; Chapman and Gray, 1973).

As established above, this modified coronary prognostic index forms a sufficient basis for comparing severity of infarction in patients treated in a coronary care unit. However, in such a unit the relation between admission delay and mortality rate is abolished, whereas elsewhere the sooner the patients are admitted after the onset of infarction the higher the mortality rate (Chapman, 1970, 1971a; Chapman and Gray, 1973; B. L. Chapman, unpublished observations). It was for this reason that the admission delays were also compared.

\section{Results}

The total numbers of cases of acute myocardial infarction treated in the general wards during the two years before the introduction of coronary care, and during the 18 months afterwards, and in the coronary care unit, were 476, 193, and 432, respectively. The mean times spent in hospital ( \pm SD) were $22.4( \pm 13.8), 20.5( \pm 13.5)$, and 21.7 $( \pm 12 \cdot 0)$ days, respectively. The differences between these means were not significant (general wards 1966 to 1968 vs. general wards 1968 to 1970 , $P>0.05$; general wards 1966 to 1968 vs. CCU, $P>0.20$; general wards 1968 to 1970 vs. CCU, $P>0 \cdot 10)$. The respective hospital mortality rates were $34 \cdot 7,34 \cdot 7$, and $17 \cdot 1$ per cent.

ADMISSION DELAY

The mean admission delay for the 427 coronary 
care unit cases in which this was known was 13.6 $( \pm 15.9)$ hours, significantly less than the 16.3 ( $\pm 19 \cdot 6)$ hours for the 435 cases treated in the general wards before the start of coronary care, and the $17 \cdot 2( \pm 20 \cdot 8)$ hours for the 167 cases treated there subsequently (for each of the two pairs, $\mathrm{P}<0.025$ ). On the other hand, the small difference between the mean admission delays for the two groups of general ward patients was not significant $(\mathbf{P}>0.30)$.

MODIFIED CORONARY PROGNOSTIC INDEX

The modified coronary prognostic index could be calculated for 414 of the patients treated in the general wards before the introduction of coronary care, 157 of those treated there subsequently, and 307 of those treated in the coronary care unit. The series studied therefore contained a total of 878 cases.

The mean modified prognostic index was higher for patients treated in the coronary care unit than for those treated in the general wards either before or after the introduction of coronary care (Table 2). These differences were highly significant, but, on the other hand, the difference between the means for the two groups of general ward patients was small and not significant $(P>0 \cdot 30)$.

\section{MORTALITY RATES}

In spite of their significantly higher mean modified prognostic index, the coronary care unit patients had a mortality rate little more than half that of the general ward patients (Table 2). The differences in mortality were highly significant, whether the coronary care unit cases were compared with general ward cases treated before $(P<0.0005)$ or after $(P<0.005)$ the introduction of coronary care. By contrast, the mortality rates were practically the same for general ward patients treated before and after the establishment of the coronary care unit, and the difference was not significant $(P>0.60)$.
CORRELATIONS BETWEEN MORTALITY RATES

AND MODIFIED PROGNOSTIC INDEX

In each of the three groups of patients studied, the mortality rate increased with increasing modified coronary prognostic index (Fig. 2, 3, 5). There was a very close linear correlation between mortality rate and modified prognostic index for patients treated in the general wards both before ( $r=0.915$, Fig. 2) and after ( $r=0.889$, Fig. 3) the introduction of coronary care, and for those treated in the coronary care unit ( $r=0.927$, Fig. 5). Each of these correlation coefficients was highly significant $(P<0.0002)$. The amount of the variation in mortality rate explained by variation in modified prognostic index was 83.8 and 79.0 per cent, respectively, for the general ward patients treated before and after the introduction of coronary care, and 86.0 per cent for the coronary care unit patients.

The rate at which mortality rate increased with increasing modified prognostic index was approximately the same in all three groups of patients. Thus the rate of increase, as measured by the regression coefficients, was 1.2 for both groups of general ward patients (Fig. 2, 3) and 1.3 for coronary care unit patients (Fig. 5). The differences between the regression coefficients were insignificant (for each of the three pairs, $P>0.95$ ).

For the coronary care unit patients, there was no mortality additional to that described by the regression coefficient, and hence chiefly explained by variation in modified prognostic index (Fig. 5). The independent constant of the regression equation, in fact, had a small negative value $(-3.5 \%)$. By contrast, the general ward patients had a large additional mortality of 15 per cent for those treated before the introduction of coronary care (Fig. 2) and 14 per cent for those treated subsequently (Fig. 3). The independent constant for each group of general ward cases (Fig. 2, 3) differed to a highly significant degree from the constant for the coronary care unit cases (Fig. 5) (for each of the two pairs,

Table 2 Distribution of patients according to period and place of initial coronary care and to value of modified prognostic index, with associated mortality

\begin{tabular}{|c|c|c|c|c|c|c|}
\hline Period & $\begin{array}{l}\text { Place of initial } \\
\text { coronary care }\end{array}$ & No. of cases & Modified coronary prog & ostic index $\star$ & Mortality rate $(\%)$ & \\
\hline Before coronary care & General wards & 414 & $13.0 \pm 15 \cdot 1\} P>0.30$ & & $30.0\} P>0.60$ & \\
\hline After coronary care & $\begin{array}{l}\text { General wards } \\
\text { Coronary care unit }\end{array}$ & $\begin{array}{l}157 \\
307\end{array}$ & $\left.\begin{array}{c}12.3 \pm 16.5 \\
16.3 \pm 17.7\end{array}\right\} P<0.01$ & $P<0.005$ & $16.3\} P<0.005$ & $P<0.0005$ \\
\hline
\end{tabular}

$\star$ Mean \pm SD. 
$P<0.0002)$. On the other hand, the independent constant for the general ward cases treated after the introduction of coronary care (Fig. 3) was not significantly different from the constant for those treated before (Fig. 2) $(\mathrm{P}>\mathbf{0} \cdot 10)$. (These significance levels, of course, take into account the spread of the mortality rates above and below the regression lines. This scatter is expressed in the standard error of estimate, which was 7.5 and 8.9 per cent, respectively, for the general ward cases treated before and after establishment of the coronary care unit, and 7.4 per cent for the coronary unit cases.)

Because of their close similarity (according to mean admission delay, modified prognostic index, time in hospital, and mortality rate, as well as results of correlation and regression analysis), the two groups of general ward patients were combined (Fig. 4). For this composite group, the degree of linear correlation between mortality rate and modified prognostic index was higher than for either of the two constituent groups alone, and even higher than for the coronary care unit group, 88 per cent of the variation in mortality rate being explained by variation in modified prognostic index. The rate of change in mortality rate with modified prognostic index was 1.2 (Fig. 4), and the difference between the regression coefficients for the combined general ward patients (Fig. 4) and the coronary care unit patients (Fig. 5) was again insignificant $(P>0.95)$. The mortality additional to that described by the regression coefficient was 15 per cent (Fig. 4), the difference between this independent constant for the combined general ward patients (Fig. 4) and that for the coronary care unit patients (Fig. 5) being highly significant $(P<0.0002)$.

\section{Discussion}

The hospital mortality rate of acute myocardial infarction fell after the introduction of intensive coronary care, but only for those patients whose initial treatment was in the coronary care unit. For these, the mortality rate was little more than half that in patients treated throughout in general wards, either before or after the establishment of the coronary care unit.

The fall in mortality rate was associated with the beginning of the coronary care unit's operation. In the five years before the unit opened the rate had varied, though not significantly, between 32 and 39 per cent (Chapman, 1970). In the seven weeks before the unit opened, it had still been 33 per cent, virtually identical with the rate in the preceding 12 months. By contrast, the overall hospital mortality rate (for combined coronary care unit and general

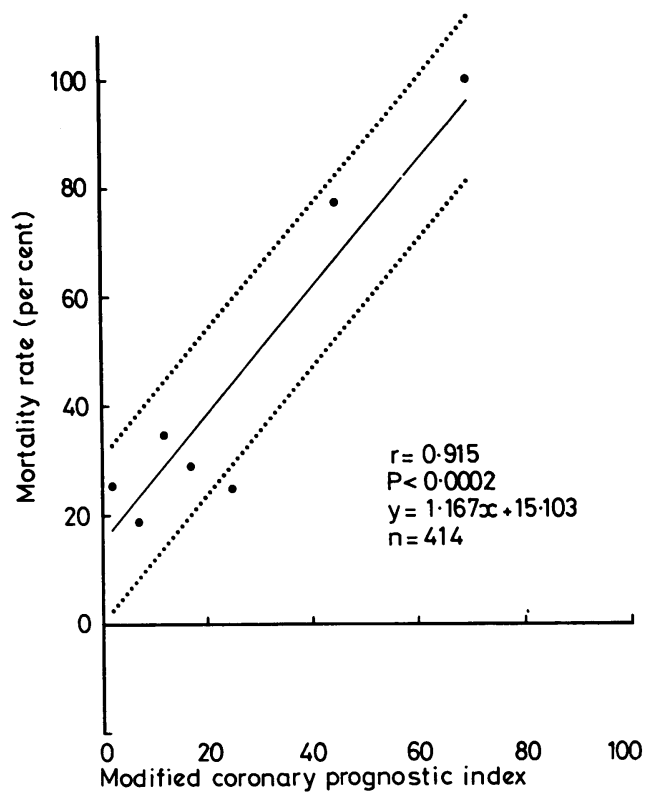

Fig. 2 General ward cases, 1 fuly 1966 to 30 fune 1968. Relation between mortality rate and modified coronary prognostic index.

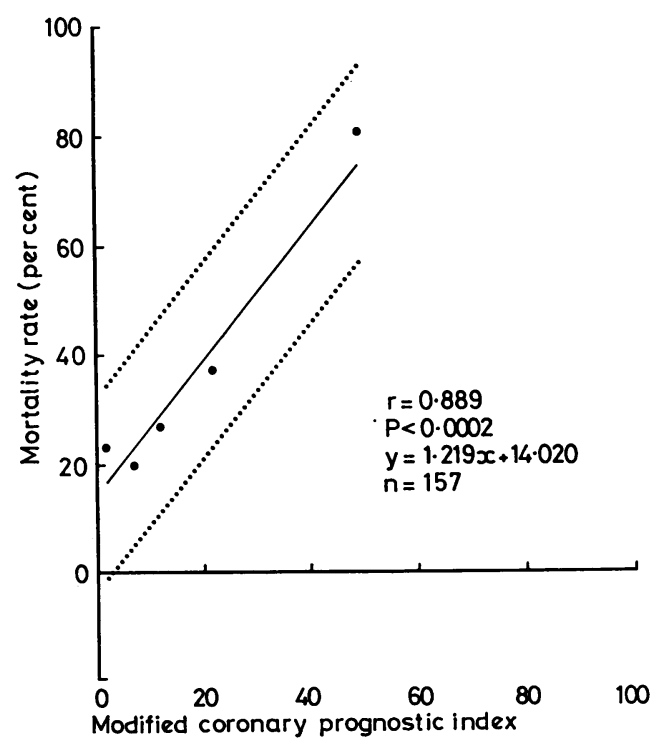

Fig. 3 General ward cases, 20 August 1968 to 19 February 1970. 


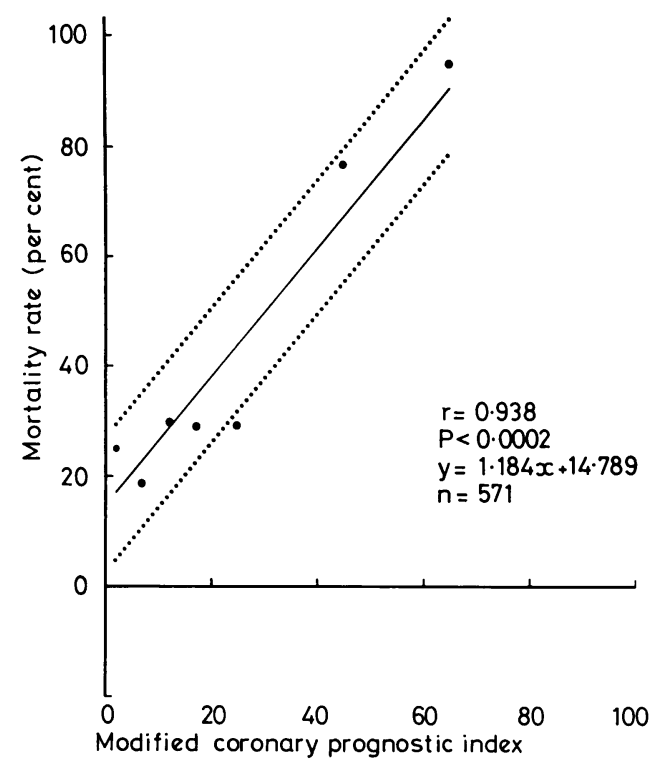

Fig. 4 General ward cases, 1 fuly 1966 to 30 fune 1968 combined with 20 August 1968 to 19 February 1970.

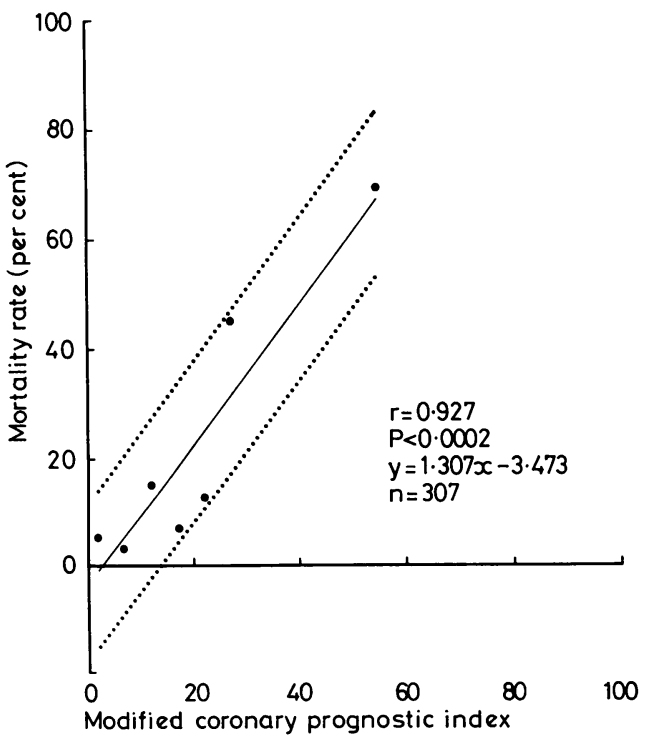

Fig. 5 Coronary care unit cases, 20 August 1968 to 19 February 1970. ward patients) fell to only 23 per cent in the first 10 weeks of the unit's operation, and never varied significantly during the next two years (B. L. Chapman, unpublished observations).

This mortality reduction was in spite of the significantly shorter mean admission delay and significantly higher mean prognostic index of the coronary care unit cases. Such differences would tend to increase, not as actually happened, significantly reduce, the mortality rate of patients treated in the unit. On the other hand, for general ward patients the mortality remained practically the same after the unit's establishment as it had been before. Using the pre-CCU experience as the standard, this persistently high general ward mortality, unlike the coronary care unit mortality, was quite in keeping with the admission delay and modified prognostic index of the patients concerned.

For each of the three groups of patients studied, there was a close and statistically highly significant linear correlation between mortality rate and modified prognostic index. Between 79 and 88 per cent of the variation in mortality rate was explained by variation in modified index. This confirmed the usefulness of the index for determining the severity of infarction. The similarly high correlation coefficients for each of the three groups showed that this was independent of the place of initial coronary care.

The ratc at which the mortality rate increased with increase in modified prognostic index was virtually the same for all three groups of patients. This rate of increase, as expressed by the regression coefficients, was 1.2 for both groups of general ward cases and 1.3 for the coronary care unit cases. Thus the regression lines were essentially parallel.

The reduction in mortality rate for patients treated in the coronary care unit was 15 per cent, and did not vary significantly over the whole range of the modified coronary prognostic index. Though the difference in mortality rate varied from 18 per cent at the lower end of the range of modified coronary prognostic index to 12 per cent at the upper end of the range, the difference between the slopes of the lines was still insignificant.

This finding that the mortality rate of all cases of acute myocardial infarction, regardless of severity, is reduced by 15 per cent means that severity of infarction should no longer be grounds for refusing admission to a coronary care unit. Admittedly, compared with the expected mortality rate of 15 per cent at the lower end of the range of modified prognostic index for patients treated in general wards, a 15 per cent reduction is a 100 per cent change, whereas compared with the expected rate of 82 per cent at the upper end of the range, a 15 per 
cent reduction is a change of only 18 per cent. Nevertheless, this still seems a worth-while reduction, and suggests that ideally coronary care should be available for all myocardial infarct patients.

The additional mortality, over and above that explained by variation in modified coronary prognostic index, reflecting severity of infarction, in general ward cases compared with coronary care unit cases, was presumably caused by untreated arrhythmias. It was pointed out previously that there are two components of the overall mortality of acute myocardial infarction treated outside coronary care units (Chapman, 1971b). The first component is directly related to the size of the infarct. The second component is unrelated to the severity of infarction. The higher mortality of such patients is generally believed to result from untreated arrhythmias (Adelson and Hoffman, 1961; Mower et al., 1964; Lown et al., 1967; Lawrie, 1969; Lovell and Prineas, 1971). It was also suggested previously that, in cases treated in a coronary care unit, the cardiac complications of acute myocardial infarction are not themselves the cause of the increased mortality associated with their presence, but are only indirectly related to the mortality rate, their occurrence merely reflecting the extent of infarction (Chapman, 1972; Chapman and Gray, 1973), to which the overall mortality rate itself is directly related (Chapman, 1971b). These complications included the arrhythmias (Chapman, 1972).

The present study had the advantage (Hill, 1955; Cochrane, 1972; Feinstein, 1973) of a concurrent control group. It also had the advantage of a retrospective control group, particularly since this was virtually identical with the concurrent group. The influence of varying diagnostic criteria on the selection of cases in different series has already been reviewed (Chapman and Gray, 1973). In the present series, the same criteria for the diagnosis of acute myocardial infarction were adhered to throughout. All clinical records and electrocardiograms were examined personally. It is often stated that hospital admission policies change over the years, so that groups of patients observed before and after the introduction of a new treatment may have different prognostic characteristics. In the present series, however, the general ward patients treated after the introduction of coronary care were very similar to those treated before. This was shown by similar admission delay, modified prognostic index, and time spent in hospital, as well as overall mortality rates, and results of linear correlation and regression analysis. For none of these was there any significant difference between the two groups. (The combining of the groups for joint comparison with the coronary care unit cases was justified by these similarities.)

However, there were differences attributable to changed admission policy for the coronary care unit cases. Their significantly shorter mean admission delay and higher mean modified prognostic index, compared with both groups of general ward patients, resulted respectively from the policy of admission soon after onset of symptoms, and the emphasis on coronary care for arrhythmias and complications, virtually all of which become more frequent as severity of infarction increases (Chapman, 1972; B. L. Chapman, unpublished observations). Thus, the policy of advising admission regardless of severity did not result in any lowering of the overall infarct severity of coronary care unit cases by diluting them with mild cases that would previously have been treated at home. In fact, just the opposite happened, and severity of infarction increased. However, it is possible that this increase was apparent only, and merely the result of improved observation and investigation in the coronary care unit (Oliver et al., 1967).

The improved results were in no way attributable to a changed duration of observation. The distribution of patients according to their time spent in hospital was similar for all three groups studied. The mean for each group was about 21 days, much longer than is necessary to observe the period of maximum mortality, which is the first day or two after infarction (Chapman and Gray, 1973). The mean number of days from infarction to death for the general ward patients treated before the introduction of coronary care was 11 days, for those treated subsequently 10 days, and for those treated in the coronary care unit 9 days.

I am not aware of any other investigation into the effect of coronary care on myocardial infarct mortality conducted along the same lines as in the present study. However, its finding of a significant mortality reduction in coronary care unit cases is supported by published studies in which, according to a wide variety of different criteria, the severity of infarction in the coronary care unit cases was probably either equal to (Killip and Kimball, 1967; Parkinson et al., 1967; Meltzer, 1968; Norris et al., 1969; Bloomfield et al., 1970; Hofvendahl, 1971; MacMillan and Brown, 1971) or greater than (Marshall et al., 1968; Woodhouse and Hunter, 1968; Robinson, 1969; Chapman, 1970; Klaus et al., 1970) that in the general ward case. This is in contradistinction to studies in which coronary care appeared to confer no benefit over general ward treatment (Linko et al., 1970; Astvad et al., 1974; Martin et al., 1974; Colling et al., 1976; Hill et al., 1977). In three of these latter studies, however, 
patients were not treated in coronary care units at all, but in either intensive care units (Linko et al., 1970; Martin et al., 1974) or a busy general admission ward, where only two-thirds of patients could even be monitored (Astvad et al., 1974). Thus only two reports presenting true coronary care unit results are at variance with the present study (Colling et al., 1976; Hill et al., 1977). In both these, however, the results were presented in the course of studies comparing hospital with home treatment, and will be referred to again later.

The uniform mortality reduction, in the present series, for infarcts of all degrees of severity as assessed with the modified prognostic index, is contrary to published opinion. It is usually stated that the greatest mortality reduction in acute myocardial infarction occurs with mild or only moderately severe infarcts, while there is little or no reduction with very severe infarcts. In only one previously published series was it claimed that the mortality reduction resulting from coronary care was uniform over any range of prognostic factors. Christiansen et al. (1971) stated that the reduction was 'constant for the sub-groups of age and sex'. However, the data presented did not fully support this claim, because though the mortality reduction was approximately the same for men and women, for the different age groups there was no consistent pattern.

The present results, of course, throw no light on the reported failure of coronary care to lower the mortality rate, as compared with treatment at home (Mather et al., 1976; Colling et al., 1976; Hill et al., 1978). In the study of Mather et al. (1976) patients were allocated randomly to home or hospital for their initial coronary care. However, only 31 per cent of cases who were already a selected group (men aged under 70 years) were actually randomised. The mortality rate for their patients $t$ :eated at home, while similar to that for those of Colling et al. (1976) and Hill et al. (1978), was less than for home-treated patients in the series of Fry and Dillane (1967) and Nichols (1968) and also, if all cases are considered, in that of Sleet (1968). Moreover, Armstrong et al. (1972) showed that, merely by varying the criteria for admission to the groups studied, the mortality rate for patients treated at home can be changed from below to considerably above that for coronary care unit patients. The present study clearly shows that, once patients are admitted to hospital, their mortality rate is significantly lowered when initial coronary care takes place in a coronary care unit.

Grateful acknowledgment is once again made of the contributions to the study of which this is a part by
Dr J. M. Duggan, Dr J. T. Holland, Dr J. N. Walker, Mr H. M. Frith, Mrs J. Bubb, and many staff members of the Royal Newcastle Hospital, Newcastle Permanent Building Society Limited, CSIRO Division of Computing Research, West Middlesex Hospital (Isleworth), Hammersmith Hospital, and the Royal Society of Medicine (London). Mr C. H. Gray, Consultant Statistician at the CSIRO, once more generously gave statistical advice, and performed the multiple regression analysis.

\section{References}

Adelson, L., and Hoffman, W. (1961). Sudden death from coronary disease. Related to a lethal mechanism arising independently of vascular occlusion or myocardial damage. fournal of the American Medical Association, 176, 129-135.

Armstrong, A., Duncan, B., Oliver, M. F., Julian, D. G., Donald, K. W., Fulton, M., Lutz, W., and Morrison, S. L. (1972). Natural history of acute coronary heart attacks. A community study. British Heart fournal, 34, 67-80.

Astvad, K., Fabricius-Bjerre, N., Kjaerulff, J., and Lindholm, J. (1974). Mortality from acute myocardial infarction before and after establishment of a coronary care unit. British Medical fournal, 1, 567-569.

Bloomfield, D. K., Slivka, J., Vossler, S., and Edelstein, J. (1970). Survival in acute myocardial infarction before and after the establishment of a coronary care unit. Chest, 57, 224-229.

Brown, K. W. G., MacMillan, R. L., Forbath, N., Mel'Grano, F., and Scott, J. W. (1963). Coronary unit. An intensivecare centre for acute myocardial infarction. Lancet, 2, 349352.

Chapman, B. L. (1970). Hospital mortality of myocardial infarction, before and after coronary care. Medical fournal of Australia, 1, 833-837.

Chapman, B. L. (1971a). Prognostic factors in acute myocardial infarction treated in a coronary care unit. Australian and New Zealand fournal of Medicine, 1, 53-62 (Corrigenda, 1, No. 3).

Chapman, B. L. (1971b). Correlation of mortality rate with serum enzyme levels in myocardial infarction. Test of efficiency of coronary care. British Heart fournal, 33, 643646.

Chapman, B. L. (1972). Relation of cardiac complications to SGOT level in acute myocardial infarction. British Heart fournal, 34, 890-896.

Chapman, B. L., and Gray, C. H. (1973). Prognostic index for myocardial infarction treated in a coronary care unit. British Heart fournal, 35, 135-141.

Christiansen, I., Iversen, K., and Skouby, A. P. (1971). Benefits obtained by the introduction of a coronary-care unit. A comparative study. Acta Medica Scandinavica, 189, 285-291.

Cochrane, A. L. (1972). Effectiveness and Efficiency. Random Reflections on Health Services. The Rock Carling Fellowship 1971. Nuffield Provincial Hospitals Trust, London.

Colling, A., Dellipiani, A. W., Donaldson, R. J., and MacCormack, P. (1976). Teesside coronary survey: an epidemiological study of acute attacks of myocardial infarction. British Medical fournal, 2, 1169-1172.

Day, H. W. (1963). Preliminary studies of an acute coronary care area. Fournal-Lancet, 83, 53-55.

Donaldson, R. J. (1978). At home or to hospital? American Heart fournal, 95, 406-408.

Feinstein, A. R. (1973). Clinical biostatistics. XXIV. The role 
of randomization in sampling, testing, allocation, and credulous idolatry. Clinical Pharmacology and Therapeutics, 14, 1035-1051.

Flynn, R. L., and Fox, S. M. (1967). Coronary care programs in the United States. Israel fournal of Medical Sciences, 3, 279-286.

Fry, J., and Dillane, J. B. (1967). Acute coronary deaths. Possible salvage? fournal of the Royal College of General Practitioners, 14, 44-49.

Hill, A. B. (1955). Principles of Medical Statistics, 6th edn, Lancet, London.

Hill, J. D., Hampton, J. R., and Mitchell, J. R. A. (1978). A randomised trial of home-versus-hospital management for patients with suspected myocardial infarction. Lancet, 1, 837-841.

Hill, J. D., Holdstock, G., and Hampton, J. R. (1977). Comparison of mortality of patients with heart attacks admitted to a coronary care unit and an ordinary medical ward. British Medical fournal, 2, 81-83.

Hofvendahl, S. (1971). Influence of treatment in a coronary care unit on prognosis in acute myocardial infarction. A controlled study in 271 cases. Acta Medica Scandinavica, Suppl. 519.

Killip, T., III, and Kimball, J. T. (1967). Treatment of myocardial infarction in a coronary care unit. A two-year experience with 250 patients. American fournal of Cardiology, 20, 457-464.

Klaus, A. P., Sarachek, N. S., Greenberg, D., Pekover, J., and Cooper, J. K. (1970). Evaluating coronary care units. American Heart fournal, 79, 471-480.

Lawrie, D. M. (1969). Ventricular fibrillation in acute myocardial infarction. American Heart fournal, 78, 424-426.

Lindholm, J., Fabricius-Bjerre, N., Astvad, K., and Kjaerulff, J. (1976). Coronary care units. American Heart fournal, 91, 673-674.

Linko, E., Koskinen, P. J., Ruosteenoja, R., Kauranen, O., and Hakala, T. (1970). Intensive care of myocardial infarction. A two-year experience with 329 patients. Acta Medica Scandinavica, 187, 117-122.

Lovell, R. R. H., and Prineas, R. J. (1971). Mechanisms of sudden death and their implications for prevention and management. Progress in Cardiovascular Diseases, 13, 482-494.

Lown, B., Fakhro, A. M., Hood, W. B., and Thorn, G. W. (1967). The coronary care unit. New perspectives and directions. Fournal of the American Medical Association, 199, 188-198.

MacMillan, R. L., and Brown, K. W. G. (1971). Comparison of the effects of treatment of acute myocardial infarction in a coronary unit and on a general medical ward. Canadian Medical Association fournal, 105, 1037-1040.

Marshall, R. M., Blount, S. G., jun, and Genton, E. (1968) Acute myocardial infarction. Influence of a coronary care unit. Archives of Internal Medicine, 122, 472-475.

Martin, S. P., Donaldson, M. C., London, C. D., Peterson, O. L., and Colton, T. (1974). Inputs into coronary care during 30 years. A cost effectiveness study. Annals of Internal Medicine, 81, 289-293.

Mather, H. G., Morgan, D. C., Pearson, N. G., Read, K. L. Q., Shaw, D. B., Steed, G. R., Thorne, M. G., Lawrence, C. J., and Riley, I. S. (1976). Myocardial infarction: a comparison between home and hospital care for patients. British Medical Fournal, 1, 925-929.

Meltzer, L. E. (1968). Presbyterian-University of Pennsylvania Medical Center, Philadelphia. In Acute Myocardial Infarction. Proceedings of a Symposium, pp. 3-7, ed D. G. Julian and M. F. Oliver. Livingstone, Edinburgh and London.

Mower, M. M., Miller, D. I., and Nachlas, M. M. (1964). Clinical features relevant to possible resuscitation in death after acute myocardial infarction. American Heart fournal, $67,437-444$.

Nichols, J. B. (1968). Myocardial infarction in general practice. Practitioner, 200, 700-701.

Norris, R. M., Brandt, P. W. T., and Lee, A. J. (1969). Mortality in a coronary-care unit analysed by a new coronary prognostic index. Lancet, 1, 278-281.

Oliver, M. F., Julian, D. G., and Donald, D. W. (1967). Problems in evaluating coronary care units. American fournal of Cardiology, 20, 465-474.

Parkinson, P. I., Wattie, W. J., and Kirk, G. M. (1967). The coronary care unit at Palmerston North Hospital. New Zealand Medical fournal, 66, 872-877.

Peterson, O. L. (1978). Myocardial infarction: unit care or home care? Annals of Internal Medicine, 88, 259-261.

Robinson, J. S. (1965). The dividend from a coronary-care unit (abstract). Medical fournal of Australia, 2, 576-577.

Robinson, J. S. (1969). Coronary care unit versus hospital mortality in acute myocardial infarction. Israel fournal of Medical Sciences, 5, 772-774.

Sleet, R. A. (1968). Report of 24 cases of myocardial infarction treated at home. British Medical fournal, 4, 675-677.

Sloman, G., and Brown, R. (1970). Hospital registration in patients with acute myocardial infarction. American Heart Fournal, 79, 761-768.

Wilburne, M., and Fields, J. (1963). Cardiac resuscitation in coronary artery disease. A central coronary care unit. fournal of the American Medical Association, 184, 453-457.

Woodhouse, S. P., and Hunter, J. D. (1968). Results of acute coronary care in a medical ward. New Zealand Medical fournal, 67, 464-469.

Wyman, M. G., and Hammersmith, L. (1968). Coronary care in the small community hospital. Diseases of the Chest, 53, 584-591.

Yeomans, K. A. (1968). Statistics for the Social Scientist, Vol. 1 and 2. Penguin, Harmondsworth.

Requests for reprints to Dr B. L. Chapman, York Wing, The Royal Newcastle Hospital, Newcastle, NSW 2300, Australia. 